\title{
РЕГИОНАЛЬНАЯ ЭКОНОМИКА
}

DOI: http:/ / dx.doi.org/10.21686/2413-2829-2018-5-182-191

\section{ТЕХНОЛОГИЧЕСКИЕ ИННОВАЦИИ КАК ФАКТОР УСТОЙЧИВОГО ЭКОНОМИЧЕСКОГО РАЗВИТИЯ РЕГИОНА}

\author{
Т. А. Воронова, А. П. Гарнов, Е. В. Логинова \\ Российский экономический университет имени Г. В. Плеханова, \\ Москва, Россия \\ С. Ю. Айвазов \\ Университет «Синергия», Москва, Россия
}

\begin{abstract}
В статье обосновываются значимость и важная роль инноваций в промышленности, рассмотрено их воздействие на экономику. Исследуются показатели, характеризующие позиции российской высокотехнологичной продукции на мировом рынке. Раскрыты причины низкой конкурентоспособности российских производителей. Показано значение новых технологий для достижения устойчивого развития промышленных предприятий. Проанализированы показатели инновационной деятельности и выявлена неравномерность развития инновационной системы в различных регионах. Авторами обоснована необходимость перехода российской промышленности на качественно новый уровень развития и определены приоритетные направления формирования инновационной инфраструктуры регионов. Отмечены особенности проведения инновационной политики в России. Выделены основные проблемы, препятствющие развитию инновационных процессов, и предложены пути их преодоления. Разработан комплекс мер для сглаживания отставания инновационного развития частного сектора от государственного и для стимулирования исследований и разработок в частном секторе. Результаты исследования могут быть использованы при корректировке региональных стратегий инновационного развития.

Ключевые слова: инновации, инновационный потенциал, инновационная политика, высокотехнологичные производства, промышленность, цифровизация, регион.
\end{abstract}

\section{TECHNOLOGICAL INNOVATION AS A FACTOR OF SUSTAINABLE ECONOMIC DEVELOPMENT OF THE REGION}

\author{
Tatyana A. Voronova, Andrei P. Garnov, Elena V. Loginova \\ Plekhanov Russian University of Economics, Moscow, Russia \\ Sergey Yu. Ayvazov \\ Synergy University, Moscow, Russia
}

The article explains the necessity and important role of innovation in industry and shows their impact on economy. There are indicators characterizing the position of Russian highly technological products on global market. Causes of low competitiveness of Russian producers were revealed. The article demonstrates the importance of new technologies for attaining sustainable development of industrial enterprises and analyzes indicators of innovation activity, which discloses the uneven development of the innovation system in different regions of the country. The authors ground the necessity of Russian industry passing over to a new level of development and identify the key lines in shaping the innovative infrastructure of regions. They underline specific features of pursuing innovation policy in Russia, highlight principle problems hindering the development of innovation processes and propose ways of their overcoming. A set of measures was designed aimed at smoothing out the lag of private sector development from the state one and at stimulating research and developments in the private sector. Research findings can be used to correct regional strategies of innovation development.

Keywords: innovation, innovation potential, innovation policy, highly technological production, industry, digitalization, region. 


\section{Введение}

$\mathrm{B}$ связи с переходом мирового сообщества на инновационный тип экономики, основанный на потоке инноваций, производстве и экспорте высокотехнологичной продукции с очень высокой добавочной стоимостью, представляет интерес вопрос обеспечения устойчивого экономического развития российских регионов за счет внедрения технологических инноваций.

Инновационная деятельность - это деятельность по реализации инновационных проектов, а также направленная на создание инновационной инфраструктуры и ее обеспечение ${ }^{1}$.

Устойчивое экономическое развитие региона можно определить как целенаправленный процесс наращивания потенциала региональной системы за счет поддержания ее динамического равновесия, мотивации хозяйственных субъектов к расширенному воспроизводству, повышению конкурентоспособности и с учетом этого к повышению уровня жизни населения [1].

Достижение устойчивого экономического развития как регионов, так и всей страны возможно лишь в русле инновационной парадигмы, которая позволяет поддерживать необходимый с точки зрения создания благоприятных условий для жизни населения уровень конкурентоспособности территории, одновременно повышая эффективность использования природных ресурсов и снижая риски для окружающей среды.

Инновационное развитие экономики в настоящее время является приоритетным направлением государственной политики. Главная цель промышленной политики «создание в РФ конкурентоспособной, устойчивой, структурно сбалансированной промышленности, способной к эффективному саморазвитию на основе интеграции в мировую технологическую среду, разработки и применения передовых промыш-

1 См.: Федеральный закон от 23 августа 1996 г. № 127-Ф3 «О науке и государственной научнотехнической политике» (ред. от 3 декабря 2012 г.). ленных технологий, нацеленных на формирование и освоение новых рынков инновационной продукции, эффективно решающей задачи обеспечения экономического развития страны» 2 .

Для российской промышленности крайне необходим новый технологический импульс, который, во-первых, позволит осуществить инновационный задел с целью получения конкурентного преимущества на мировом рынке, а во-вторых, станет источником быстрого экономического роста.

В современном мире новым источником экономического роста стали цифровые технологии. Экспоненциальное развитие цифровых технологий, системность, глубина и масштаб их проникновения наталкивают на мысль, что они приведут к появлению новых бизнес-моделей и способов создания стоимости. Цифровые технологии сами по себе не являются новшеством, но формирование глобального информационного пространства и интеграция цифровых технологий почти во все сферы жизни людей неуклонно трансформируют мировую экономику.

\section{Оценка конкурентоспособности российской инновационной продукции на мировом рынке}

С целью изучения перспектив инновационного развития оценим уровень международной конкурентоспособности российской высокотехнологичной продукции. Согласно методологии Всемирного банка, под высокотехнологичной продукцией понимается продукция с высокой интенсивностью НИОКР (например, продукция аэрокосмической промышленности, компьютерная техника, фармацевтика, научные, измерительные, электрические приборы).

К основным показателям, характеризующим конкурентоспособность высокотехнологичной продукции на мировом рынке,

2 Постановление Правительства Российской Федерации от 15 апреля 2014 г. № 328 «Об утверждении государственной программы Российской Федерации «Развитие промышленности и повышение ее конкурентоспособности» (ред. от 30 марта 2018 г.). 
относятся объем экспорта высокотехнологичной продукции и ее доля в экспорте.
Оценим место России в мировых рейтингах по указанным показателям (табл. 1).

Т а блица 1

Рейтинг стран по высокотехнологичному экспорту в 2015-2016 гг. ${ }^{*}$

\begin{tabular}{|c|c|c|c|c|c|}
\hline \multirow{2}{*}{$\begin{array}{l}\text { Место } \\
\text { в мире }\end{array}$} & \multirow{2}{*}{ Страна } & \multicolumn{2}{|c|}{$\begin{array}{c}\text { Высокотехнологичный } \\
\text { экспорт, млрд долл. }\end{array}$} & \multicolumn{2}{|c|}{$\begin{array}{l}\text { Доля высокотехнологичной продукции } \\
\text { в экспорте промышленных товаров, \% }\end{array}$} \\
\hline & & 2015 & 2016 & 2015 & 2016 \\
\hline 1 & Китай & 273,1 & 496,0 & 30,5 & 25,2 \\
\hline 2 & Германия & 163,2 & 189,6 & 17,1 & 16,9 \\
\hline 3 & США & 219,0 & 153,2 & 30,1 & 20,0 \\
\hline 4 & Сингапур & 124,7 & 126,3 & 98,7 & 67,4 \\
\hline 5 & Республика Корея & 93,4 & 118,4 & 32,1 & 26,6 \\
\hline 6 & Франция & 81,5 & 103,8 & 21,5 & 26,7 \\
\hline 7 & Япония & 129,2 & 92,9 & 22,1 & 16,2 \\
\hline 8 & Великобритания & 119,4 & 68,3 & 33,9 & 21,8 \\
\hline 9 & Малайзия & 63,5 & 55,6 & 53,8 & 43,0 \\
\hline 30 & Россия & 3,9 & 6,6 & 7,8 & 10,7 \\
\hline
\end{tabular}

* Cocmaßлено no: URL: http://wdi.worldbank.org/table/5.13\#

Как видно из табл. 1, Россия играет незначительную роль на мировом рынке высокотехнологичной продукции. В 2016 г. она занимала 30-е место в рейтинге стран по объему высокотехнологичного экспорта, который составлял 6,6 млрд долларов, что не превышает 0,3\% мирового. Доля высокотехнологичного экспорта в объеме экспорта промышленных товаров из России невысока - 10,7\%.

Негативное влияние на высокотехнологичный экспорт оказывают международные санкции. Ранее крупнейшими потребителями были США и Германия, но сейчас эти рынки для многих продуктов закрыты. Основными направлениями российского экспорта по-прежнему остаются страны СНГ.

Поддержка высокотехнологичного экспорта - один из приоритетных государственных проектов. В рамках повышения конкурентоспособности российской инновационной продукции на мировом рынке действуют различные механизмы поддержки экспортеров: субсидирование, льготное кредитование, меры налогового и таможенного стимулирования, оказание помощи в продвижении российских товаров на зарубежные рынки, создание благоприятной институциональной среды и т. д.

Несмотря на то, что в стране действует много программ поддержки высокотехно- логичного экспорта, присутствие России на мировых рынках высоких технологий почти незаметно.

По мнению автора, причинами низкой конкурентоспособности российской продукции являются:

- низкий уровень технологического развития;

- низкий уровень производительности труда;

- высокий уровень затрат на производСтво;

- медленная адаптация российских производителей к изменению конъюнктуры рынка;

- значительная доля устаревших основных фондов.

В 2015 г. доля старых мощностей в обрабатывающей промышленности (без учета нефтепереработки) составляла чуть более четверти, средний возраст мощностей 12 лет (загруженных - 10,5 лет, незагруженных - 14,5 лет). К старым относятся мощности, которые были введены более 15 лет назад.

Средневзвешенное значение доли неконкурентоспособных мощностей в обра-

1 Анализ важнейших структурных характеристик производственных мощностей обрабатывающей промышленности России. - URL: http://csr.ru/wpcontent/uploads/2017/01/Doklad_promyshlennyemoshhnosti.pdf (дата обращения: 26.06.2018). 
батывающей промышленности (без нефтепереработки) составляет порядка 13-14\%. К неконкурентоспособным мощностям относятся мощности с возрастом свыше 10 лет, незагружаемые по меньшей мере последние 5 лет.
Как видно из табл. 2, доля неконкурентных и устаревших мощностей особенно высока в металлургии, машиностроении и производстве некоторых непродовольственных товаров.

Доля неконкурентоспособных мощностей и старых мощностей по видам деятельности в 2015 г.* (в \%)

\begin{tabular}{|l|c|c|}
\hline & $\begin{array}{c}\text { Доля старых } \\
\text { мощностей }\end{array}$ & $\begin{array}{c}\text { Доля неконкурентоспособных } \\
\text { мощностей }\end{array}$ \\
\hline Производство машин и оборудования & 39 & 26 \\
\hline Производство кожи, кожаных изделий, обуви & 50 & 22 \\
\hline Производство стройматериалов & 37 & 19 \\
\hline Производство транспортных средств и оборудования & 29 & 17 \\
\hline Химическое производство & 42 & 14 \\
\hline Производство пищевых продуктов & 14 & 14 \\
\hline Текстильное и швейное производство & 26 & 12 \\
\hline Целлюлозно-бумажное производство, издательская деятельность & 44 & 11 \\
\hline Металлургическое производство и производство металлоизделий & 53 & 10 \\
\hline
\end{tabular}

* Составлено по: Анализ важнейших структурных характеристик производственных мощностей обрабатывающей промышленности России / Центр стратегических разработок. - URL: http://csr.ru/wp-content/uploads/2017/01/Doklad_ promyshlennye-moshhnosti.pdf

Количество технически развитых промышленных предприятий в России невелико. Так, плотность роботизации промышленности намного ниже среднемирового показателя. В 2016 г. в России на 10 тыс. работников предприятий приходился один промышленный робот, в среднем в мире - 69 роботов ${ }^{1}$.

Следует отметить, что промышленное производство в ведущих странах мира развивается с преобладанием высокотехнологичных отраслей. Основой современной экономической динамики являются процессы новой индустриализации, которые представляют собой радикальное технологическое перевооружение материального производства. Только курс на технологическую модернизацию позволит России обеспечить конкурентоспособность высокотехнологичной продукции как на внешнем, так и на внутреннем рынке.

Сейчас у российских предприятий есть возможность обновить мощности и сократить технологическое отставание от зару-

\footnotetext{
1 По данным Национальной ассоциации участников рынка робототехники. - URL: http://robotunion.ru/ ru/analitika (дата обращения: 20.06.2018).
}

бежных лидеров, совершив мощнейший опережающий рывок.

\section{Цифровые технологии В промышленности}

\section{и их воздействие на экономику}

Использование цифровых технологий в промышленности позволяет выйти на качественно новый уровень и в несколько раз повысить эффективность предприятий.

Современные информационные системы позволяют сделать процесс производства полностью управляемым и прозрачным. Например, они дают возможность предприятиям проводить полный поэтапный анализ своих внутренних вертикальных цепочек создания стоимости, а также с партнерами по горизонтальной цепочке создания стоимости (поставщиками, потребителями и другими партнерами). Для этого на предприятиях создается единое информационное пространство: совокупность баз данных, технологий и регламентов, информационно-телекоммуникационных систем и сетей, интегрированных с основным и вспомогательным технологическим оборудованием. 
Вертикальная интеграция в цепочке со3дания стоимости объединяет все данные об операционных процессах, их эффективности, управлении качеством, операционном планировании в режиме реального времени в интегральной сети в рамках всей организации, начиная от разработки продуктов и закупок и заканчивая производством, логистикой и обслуживанием.

Цифровые технологии позволяют выполнить сквозную автоматизацию всех процессов, связанных с созданием, выпуском и реализацией продукции. Для этого вся информация о продукции и производственных процессах переводится в цифровой вид, и создается так называемый цифровой двойник - виртуальное воспроизведение реального физического объекта (например детали), процесса или системы. Благодаря виртуальному моделированию появляется возможность в реальном времени управлять всеми факторами, влияющими на стоимость и качество изделия еще до начала его производства, выявлять возможные проблемы в конструкции, находить оптимальные параметры технологических процессов, уменьшить скорость принятия технических решений и стоимость получения требуемых характеристик изделия.

Цифровые технологии выводят на новый уровень управление качеством продукции. Если раныше для этого использовались организационные методы (например, на производстве действовали службы контроля качества), то сейчас к ним добавились и программно-аппаратные комплексы. К ним относятся, к примеру, системы IIоT (промышленного Интернета вещей), которые автоматизируют часть функций и, как следствие, снижают вероятность человеческих ошибок. В результате снижается процент брака, уменьшается число ошибок, вызванных человеческим фактором.

Цифровые технологии создают новые возможности для анализа потребительского поведения. Одновременно и потребители благодаря цифровым технологиям по- лучают больше возможностей для оценки качества товара и обоснованности его цены.

Необходимо отметить, что цифровизация повышает прозрачность процессов не только внутри предприятия, но и для потребителей его продукции. Объем данных в цепочке поставок увеличивается, как и объем данных, предоставленных клиентам.

Цифровые технологии дают возможность быстрой переналадки производственных мощностей, например, при изменении требований потребителей. В результате предприятие может производить продукцию, соответствующую индивидуальным нуждам конкретного потребителя по цене, которая сравнима с ценой при крупносерийном производстве.

Кроме того, цифровые технологии позволяют повысить эффективность использования продукции. Например, дистанционный мониторинг поможет своевременно выявить неполадки в работе оборудования, увеличить срок его использования за счет оптимальной загрузки.

В условиях, когда инновации появляются очень быстро, услуги основываются на сборе и обработке информации, а функциональность изделия оценивается с помощью аналитики, у предприятий возникает потребность в новых формах сотрудничества. Несмотря на сильную конкуренцию, компании осуществляют совместные проекты по реализации инноваций. Одним из таких примеров является сотрудничество компании Siemens, которая направляет на исследования и разработки около 4 млрд долларов в год, с Ayasdi инновационной компанией, специализирующейся в области машинного обучения. Данное партнерство позволяет Siemens решить непростую задачу по генерации идей на основе работы с большим массивом данных. Ayasdi в свою очередь может протестировать их подход к анализу данных на основе реальной информации, а также увеличить присутствие на рынке [5].

Внедрение Интернета в производственный процесс и последовательная верти- 
кальная и горизонтальная интеграция процессов в перспективе приведут к объединению предприятиями своих станков, складских систем и средств производства в киберфизические системы (Cyber Physical Systems - CPS) с возможностью независимо обмениваться данными, инициировать определенные действия и самостоятельно управлять друг другом. Это позволит внести кардинальные улучшения в производственные процессы, проектно-конструкторские работы, использование сырья и материалов, а также в процессы управления цепочками поставок и жизненным циклом [3. - С. 21].

Основные направления технологического развития промышленности:

- цифровое моделирование;

- большие данные;

- автономные роботы;

- горизонтальная и вертикальная интеграция информационных систем;

- промышленный Интернет вещей;

- облачные технологии;

- аддитивные технологии;

- дополненная и виртуальная реальность.

Чтобы не впасть в технологическую зависимость и не остаться на низком уровне эффективности и производительности труда, Россия должна самостоятельно генерировать собственные передовые разработки и научные решения в эти направления. При этом важно не просто заместить ключевые иностранные технологии, а добиться практически полной импортонезависимости промышленности.

\section{Приоритетные направления формирования инновационной инфраструктуры регионов Российской Федерации}

Ускоренное технологическое развитие промышленности невозможно без прочного фундамента - инновационной инфраструктуры.

В настоящее время элементы инновационной инфраструктуры в виде научных организаций, разрабатывающих новые идеи и технологии, предприятий, производящих инновационную продукцию, и инновационных центров представлены практически в каждом субъекте Российской Федерации. Однако уровень развития инновационной системы в различных регионах очень неоднороден. Так, Центральный федеральный округ заметно опережает остальные округа по показателям инновационного развития (табл. 3), особенно по числу организаций и численности персонала, выполнявших научные исследования и разработки.

Каждый субъект Российской Федерации в разной степени уделяет внимание развитию инновационной деятельности. В большинстве регионов приняты документы, направленные на долгосрочное развитие, согласованные с Концепцией долгосрочного социально-экономического развития Российской Федерации на период до 2020 года, в которой содержатся разделы, посвященные развитию инновационной деятельности регионов. К таким документам относятся стратегии социальноэкономического развития регионов, региональные целевые программы, а также другие нормативные документы.

Так, например, в Самарской области действуют Стратегия социально-экономического развития Самарской области на период до 2030 года, утвержденная в 2017 г., и государственные программы «Развитие промышленности Самарской области и повышение ее конкурентоспособности до 2020 года», «Инновационное развитие машиностроительного комплекса до 2020 года». Базовыми законодательными актами в сфере инноваций являются закон «О государственной поддержке инновационной деятельности на территории Самарской области» и закон «Об инвестициях и государственной поддержке инвестиционной деятельности в Самарской области» [4. - С. 171]. 
Состояние инновационной деятельности в федеральных округах Российской Федерации в 2016 г.*

\begin{tabular}{|c|c|c|c|c|c|}
\hline & $\begin{array}{c}\text { Число организа- } \\
\text { ций, выполняв- } \\
\text { ших научные } \\
\text { исследования } \\
\text { и разработки }\end{array}$ & $\begin{array}{c}\text { Численность } \\
\text { персонала, заня- } \\
\text { того научными } \\
\text { исследованиями } \\
\text { и разработками }\end{array}$ & $\begin{array}{c}\text { Затраты на } \\
\text { технологи- } \\
\text { ческие ин- } \\
\text { новации, } \\
\text { млн руб. }\end{array}$ & $\begin{array}{c}\text { Объем инно- } \\
\text { вационных } \\
\text { товаров, ра- } \\
\text { бот, услуг, } \\
\text { млн руб. }\end{array}$ & $\begin{array}{c}\text { Совокупный уро- } \\
\text { вень инновационной } \\
\text { активности органи- } \\
\text { заций в промыш- } \\
\text { ленности, \% }\end{array}$ \\
\hline $\begin{array}{l}\text { Российская } \\
\text { Федерация }\end{array}$ & 4032 & 722291 & 1284590,3 & 4364321,7 & 10,6 \\
\hline $\begin{array}{l}\text { Центральный } \\
\text { федеральный } \\
\text { округ }\end{array}$ & 1461 & 372293 & 528154,7 & 1677915,6 & 11,6 \\
\hline $\begin{array}{l}\text { Северо- } \\
\text { Западный феде- } \\
\text { ральный округ }\end{array}$ & 494 & 95118 & 115306,5 & 337196,7 & 9,0 \\
\hline $\begin{array}{l}\text { Южный феде- } \\
\text { ральный округ }\end{array}$ & 306 & 28011 & 66255,6 & 246768,3 & 10,0 \\
\hline $\begin{array}{l}\text { Северо- } \\
\text { Кавказский фе- } \\
\text { деральный округ }\end{array}$ & 160 & 7655 & 7896,5 & 37048,9 & 3,2 \\
\hline $\begin{array}{l}\text { Приволжский } \\
\text { федеральный } \\
\text { округ }\end{array}$ & 689 & 104304 & 258847,1 & 1418303,8 & 12,3 \\
\hline $\begin{array}{l}\text { Уральский фе- } \\
\text { деральный округ }\end{array}$ & 258 & 46437 & 153891,2 & 363786,5 & 10,9 \\
\hline $\begin{array}{l}\text { Сибирский фе- } \\
\text { деральный округ }\end{array}$ & 481 & 55281 & 97864,0 & 210278,5 & 8,2 \\
\hline $\begin{array}{l}\text { Дальневосточ- } \\
\text { ный федераль- } \\
\text { ный округ }\end{array}$ & 183 & & 56374,7 & 73023,4 & 9,0 \\
\hline
\end{tabular}

* Составлено по: Индикаторы инновационной деятельности. 2018 : статистический сборник / Н. В. Городникова, Л. М. Гохберг, К. А. Дитковский и др.; Нац. исслед. ун-т «Высшая школа экономики». - М. : НИУ ВШЭ, 2018; Регионы России. Социально-экономические показатели. 2017 : статистический сборник / Росстат. - М., 2017.

Во многих регионах создаются специализированные научные центры, рабочие группы, экспертные советы, которые положительно влияют на развитие инновационной деятельности.

Тем не менее инновационная активность организаций в промышленности находится на низком уровне во всех федеральных округах (см. табл. 3). Одной из причин этого является отсутствие мотивации. Слабая конкуренция не стимулирует предприятия развивать конкурентные преимущества и повышать эффективность производства.

Особенно низкую восприимчивость к инновациям имеют региональные предприятия. В регионах преобладают производства, относящиеся к отсталым технологическим укладам. Задача по развитию малых и средних инновационных предприятий сопряжена с большими трудностями, поскольку они реализуют продук- цию на местных рынках и ориентируются на технико-технологическую оснащенность местных предприятий.

Для стимулирования инновационной активности промышленных предприятий необходимо развивать конкуренцию, мотивирующую их к инновациям. При постоянно увеличивающемся числе производителей инновационной продукции и ужесточении конкуренции предприятия не смогут остаться жизнеспособными без постоянного внедрения инноваций.

Рост числа производителей возможен лишь при наличии устойчивого спроса на продукцию. Обеспечить спрос можно за счет упрощения выхода высокотехнологичных компаний на новые, зарубежные рынки. Для этого необходимо уменьшать количество бюрократических процедур, упрощать валютный контроль и чрезмерный таможенный контроль, оказывать информационную, консультационную и 
организационную поддержку высокотехнологичным компаниям.

Структура внутренних затрат на исследования и разработки в России отличается от ведущих стран. Основным источником финансирования исследований и разработок в России выступает государство, в то время как за рубежом - частный сектор (рисунок).

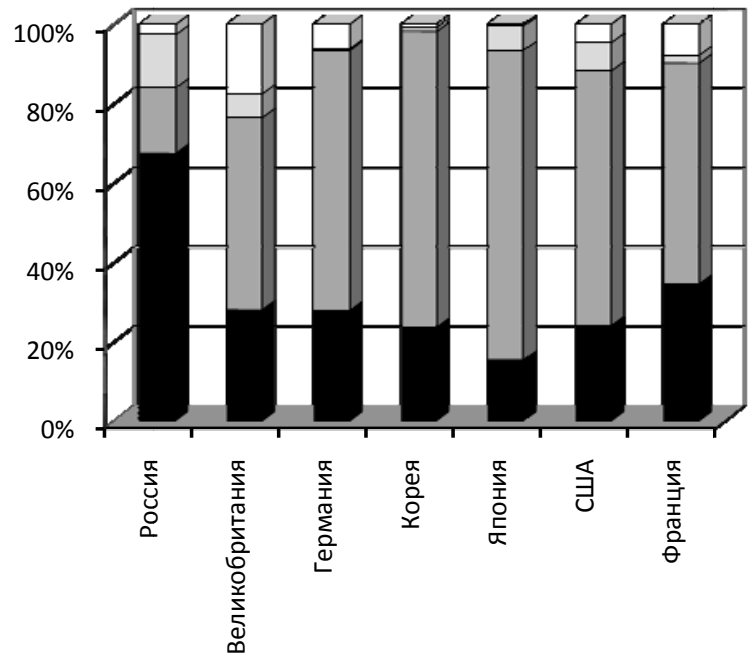

Источники правительственного сектора 口Другие национальные источники
口Источники предпринимательского сектора 口Средства иностранных источников

Рис. Структура внутренних затрат на исследования и разработки по источникам финансирования в 2015 г.

В 2015 г. 67,5\% затрат на исследования и разработки в России пришлись на источники правительственного сектора, что намного ниже, чем в среднем в странах ОЭСР [2].

Для сглаживания отставания инновационного развития частного сектора от государственного и стимулирования исследований и разработок в частном секторе региональным органам власти рекомендуется осуществить следующие виды государственной поддержки:

- развивать систему государственночастного партнерства в инновационной copepe;

- оказывать финансовую поддержку малому инновационному бизнесу;

- создавать благоприятный инвестиционный климат для привлечения финансирования со стороны частного бизнеса и венчурного капитала;

- способствовать международному сотрудничеству и кооперации в сфере инноваций;
- обеспечить спрос на высокотехнологичную продукцию частных компаний за счет государственных закупок;

- увеличить эффективность функционирования технико-внедренческих особых экономических зон;

- расширить инструментарий по поддержке инновационных кластеров;

- повышать качество работы инновационной инфраструктуры.

При разработке целевых программ развития инновационной деятельности необходимо учитывать региональные конкурентные преимущества, т. е. превосходство в экономических, социальных и иных сферах развития, делающие его в сравнении с другими регионами более привлекательным для инвесторов, предпринимателей высококвалифицированных работников и т. д. Найти конкурентные преимущества регионам поможет Стратегия пространственного развития страны до 2025 года. Разработку документа планируется завершить в 2018 г. Данная Стратегия позволит 
определить экономическую специализацию каждого субъекта Российской Федерации, расставить приоритеты в развитии, создать ориентир для властей и бизнеса в принятии решений по инвестициям, решить проблему избыточной конкуренции.

\section{Заключение}

Результаты проведенного исследования подтверждают необходимость ориентации российской промышленности на инновационный путь развития. Курс на технологическую модернизацию промышленности позволит обеспечить конкурентоспособность на внутреннем и внешнем рынках высокотехнологичной продукции и одновременно решить проблемы экономической самостоятельности и устойчивого раз- вития регионов. Важность инновационного пути развития экономики понимается государством. Для этого разрабатываются стратегии инновационного развития как на федеральном, так и региональных уровнях.

В настоящее время Россия имеет слабую позицию на мировом рынке высокотехнологичной продукции. Неоднородное развитие инновационной системы в различных регионах Российской Федерации, а также недостаточная мотивация со стороны региональных предприятий для проведения технологических инноваций, обусловленная слабой конкуренцией, являются серьезными ограничениями для реализации целей и задач политики государства в сфере инноваций.

\section{Список литературы}

1. Жукова В. А. Анализ факторов, влияющих на устойчивое развитие региона // Вестник Таганрогского института управления и экономики. - 2011. - № 1. - URL: https:// cyberleninka.ru/article/n/analiz-faktorov-vliyayuschih-na-ustoychivoe-razvitie-regiona (дата обращения: 27.06.2018).

2. Затраты и источники финансирования научных исследований и разработок. Вып. 6 / Е. В. Березина, К. В. Лебедев, Н. А. Плужнова и др. - М. : ФГБНУ НИИ РИНКЦЭ, 2017.

3. Под знаменем цифровой революции: настоящее и будущее // Цифровое производство: сегодня и завтра российской промышленности. - 2017. - № 1. - URL: http://up-pro.ru/imgs/specprojects/digital-pro/Digital_production.pdf (дата обращения: 20.06.2018).

4. Термелева А. Е. Содержание инновационного потенциала региона // Стратегические ориентиры развития экономических систем в современных условиях : межвузовский сборник статей / под общ. ред. Н. А. Дубровиной. - Самара : Издательство «Самарский университет», 2014. - Вып. 2.

5. Шваб К. Четвертая промышленная революция. - М. : Эксмо, 2016.

\section{References}

1. Zhukova V. A. Analiz faktorov, vliyayushchikh na ustoychivoe razvitie regiona [Analysis of Factors Affecting the Sustainable Development of the Region]. Vestnik Taganrogskogo instituta upravleniya i ekonomiki [Bulletin of the Taganrog Institute of Management and Economics], 2011, No. 1. (In Russ.). Available at: https://cyberleninka.ru/article/n/analiz-faktorovvliyayuschih-na-ustoychivoe-razvitie-regiona (accessed 27.06.2018).

2. Zatraty $\mathrm{i}$ istochniki finansirovaniya nauchnykh issledovaniy $\mathrm{i}$ razrabotok [Costs and Sources of Funding for Research and Development], Issue 6. E. V. Berezina, K. V. Lebedev, N. A. Pluzhnova and al. Moscow, FGBNU NII RINKTSE, 2017. (In Russ.).

3. Pod znamenem tsifrovoy revolyutsii: nastoyashchee i budushchee [Under the Banner of the Digital Revolution: the Present and the Future]. Tsifrovoe proizvodstvo: segodnya $i$ zavtra 
rossiyskoy promyshlennosti [Digital Production: Today and Tomorrow of Russian Industry], 2017, No. 1. (In Russ.). Available at: http://up-pro.ru/imgs/specprojects/digital-pro/Digital_ production.pdf (accessed 20.06.2018).

4. Termeleva A. E. Soderzhanie innovatsionnogo potentsiala regiona [Contents of the Innovative Potential of the Region]. Strategicheskie orientiry razvitiya ekonomicheskikh sistem $v$ sovremennykh usloviyakh, mezhouzovskiy sbornik statey [Strategic Guidelines for the Development of Economic Systems in Modern Conditions. Interuniversity digest of articles], edited by N. A. Dubrovina. Samara, Izdatel'stvo «Samarskiy universitet», 2014, Issue 2. (In Russ.).

5. Shvab K. Chetvertaya promyshlennaya revolyutsiya [The Fourth Industrial Revolution]. Moscow, Eksmo, 2016. (In Russ.).

\section{Сведения об авторах}

\section{Татьяна Андреевна Воронова}

доктор экономических наук, профессор, проректор по учебной работе и имущественному комплексу РЭУ им. Г. В. Плеханова.

Адрес: ФГБОУ ВО «Российский экономический университет имени Г. В. Плеханова», 117997,

Москва, Стремянный пер., д. 36.

E-mail: Voronova.TA@rea.ru

\section{Андрей Петрович Гарнов}

доктор экономических наук, профессор кафедры экономики промышленности РЭУ им. Г. В. Плеханова.

Адрес: ФГБОУ ВО «Российский экономический университет имени Г. В. Плеханова», 117997, Москва, Стремянный пер., д. 36.

E-mail: profgarnov@yandex.ru

\section{Елена Вячеславовна Логинова}

кандидат экономических наук, доцент, старший научный сотрудник научной школы «Управление человеческими ресурсами» РЭУ им. Г. В. Плеханова.

Адрес: ФГБОУ ВО «Российский экономический университет имени Г. В. Плеханова», 117997, Москва, Стремянный пер., д. 36.

E-mail: ites-log@yandex.ru

\section{Сергей Юрьевич Айвазов}

кандидат экономических наук, доцент кафедры общего и стратегического менеджмента Университета «Синергия». Адрес: негосударственное образовательное частное учреждение высшего образования «Московский финансово-промышленный университет "Синергия"», 129090,

Москва, ул. Мещанская, д. 9/4, стр. 1.

E-mail: usliga@yandex.ru

\section{Information about the authors}

Tatiana A. Voronova

Doctor of Economics, Professor,

Vice-Rector for Academic Affairs and Property

Complex of the PRUE.

Address: Plekhanov Russian University

of Economics, 36 Stremyanny Lane,

Moscow, 117997,

Russian Federation.

E-mail: Voronova.TA@rea.ru

\section{Andrei P. Garnov}

Doctor of Economics, Professor

of the Department for Industrial Economics

of the PRUE.

Address: Plekhanov Russian University

of Economics, 36 Stremyanny Lane, Moscow, 117997, Russian Federation.

E-mail: profgarnov@yandex.ru

\section{Elena V. Loginova}

PhD, Assistant Professor, Senior Research Associate of the Scientific School of Human Resources Management of the PRUE. Address: Plekhanov Russian University of Economics, 36 Stremyanny Lane, Moscow, 117997,

Russian Federation.

E-mail: ites-log@yandex.ru

\section{Sergey Yu. Ayvazov}

$\mathrm{PhD}$, Assistant Professor of the Department For General and Strategic Management of the Synergy University.

Address: Non-state private educational institution of higher professional education "Moscow University for Industry and Finance "Synergy"", 1 building, 9/4 Meshchanskaya Str., Moscow, 129090, Russian Federation.

E-mail: usliga@yandex.ru 